\title{
Inhibition of Turnip Vein Clearing Virus Movement in Seeds of Infected Arabidopsis thaliana Plant; A Microscopic Study
}

\author{
Lilia Gallegos ${ }^{*}$, Kristine Fambrough ${ }^{*}$, Robert T. Lartey ${ }^{* *}$, and Soumitra Ghoshroy ${ }^{*}$ \\ *Electron Microscopy Laboratory, New Mexico State University, Las Cruces, NM 88003 \\ ${ }^{* *}$ USDA-ARS Northern Plains Agricultural Research Laboratory, Sidney, MT 59270
}

Viral movement in host plants is an important factor for development of disease. Following initial infection, plant viruses move through plasmodesmata (cell junctions in plants) to spread cell-to-cell until they reach vasculature. ${ }^{1}$ Viruses then move systemically through the vasculature and establish disease. Over the past decade, Arabidopsis thaliana has emerged as a model system to study various plant processes and plant-microbe interactions. Turnip vein clearing virus (TVCV), a tobamovirus has recently been shown to infect Arabidopsis. ${ }^{2}$ Although the virus infects vegetative and reproductive tissues, its apparent inability to spread to seeds prevents seed transmission of TVCV. In this study, we investigated the inhibition of viral movement in mature reproductive structures of Arabidopsis thaliana using light, confocal laser scanning, and transmission electron microscopy.

Arabidopsis thaliana (ecotype Columbia) plants were grown from seeds. Before the emergence of the flowering stalk, two rosette leaves per plant were mechanically inoculated using a dilute TVCV virion suspension. After the $8^{\text {th }}$ day of inoculation, lower uninoculated rosette leaf, upper cauline leaf, flower and seed pods were analyzed by SDS-polyacrylamide gel to detect the presence of coat protein (CP), an indicator for presence of virus. Intact flower samples from systemically infected plants were fixed, dehydrated, and embedded in paraffin and Spurr's epoxy resin. The paraffin embedded samples were sectioned longitudinally and immunolabeling was performed using anti-TVCV CP antibody followed by Cy5-conjugated secondary antibody. Thick longitudinal sections were made from the resin embedded samples and photographed in a Zeiss Axioplan microscope. Same blocks were used to generate ultrathin longitudinal sections and observed under a Hitachi H7000 TEM. Postsection immunolabeling was performed using anti-TVCV CP antibody followed by $12 \mathrm{~nm}$ colloidal gold conjugated secondary antibody.

Infected Arabidopsis plants showed presence of viral coat protein in whole seedpod and whole flower (fig. 1b protein gel). Later, plants grown from seeds of infected plants showed total absence of virus infection (fig. 1a shows absence of coat protein) indicating absence of seed transmission. The confocal image (fig. 2) shows absence of virus particles in the seeds of infected flower and heavy presence of virus in ovary wall and all other areas of the flower. Thick longitudinal sections of flower (fig $3 \mathrm{a}$ and $3 \mathrm{~b}$ ) and a low magnification TEM image (fig 4a) show the anatomy of ovary and the distribution of virus particles as revealed by the immunofluorescence study. The TEM images (fig. $4 b, c)$ show a heavy thickening of the innermost cell layer of the ovary facing the seeds as opposed to a much thinner seed wall. No virus particles were observed in the seed and it was further confirmed by immunoelectron microsopy. The thick innermost cell layer of the ovary seems to block movement of virus into the seeds resulting in development of virus free seeds. However, the actual cause of inhibition of viral movement beyond the ovary wall is yet to be understood. Future study will be carried out to identify a potential host factor, if any blocking virus movement in seeds.

References:

1. Ghoshroy S., Lartey R., Sheng J. and Citovsky V. (1997) Ann Rev Plant Physiol Plant Mol Biol 48: $27-50$

2. Lartey R., Ghoshroy S., Ho J. and Citovsky V. (1997) Plant J 12(3): 537-545 


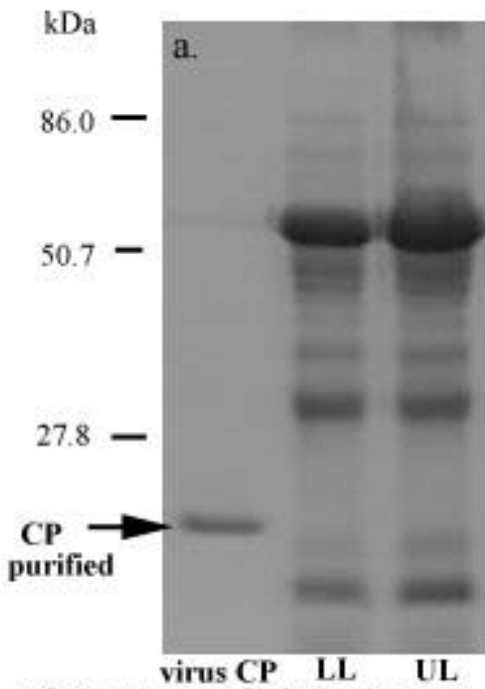

FIG. 1a. Absence of infection in plants grown from seeds collected from an infected plant. CP-coat protein; LL-lower leaf; UL-upper leaf

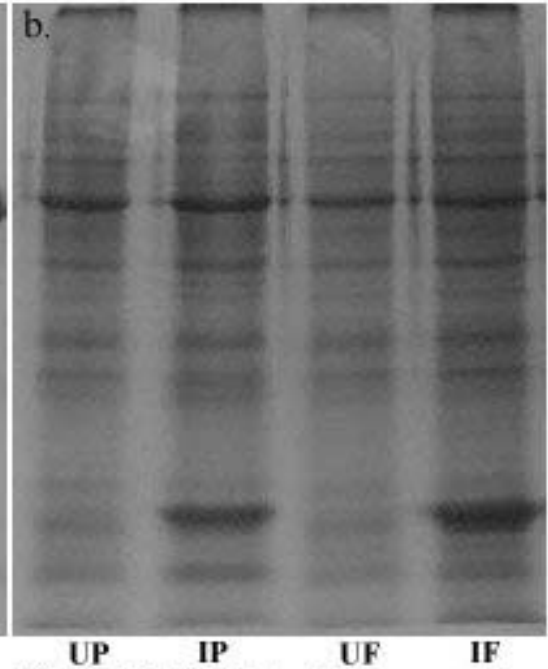

FIG. Ib. SDS-PAGE showing presence of virus $C P$ in infected flowers and seed pod Uninfected plants show no virus. UP-uninfected seed pod; IP-infected seed pod; UF-uninfected flower; IF-infected flower

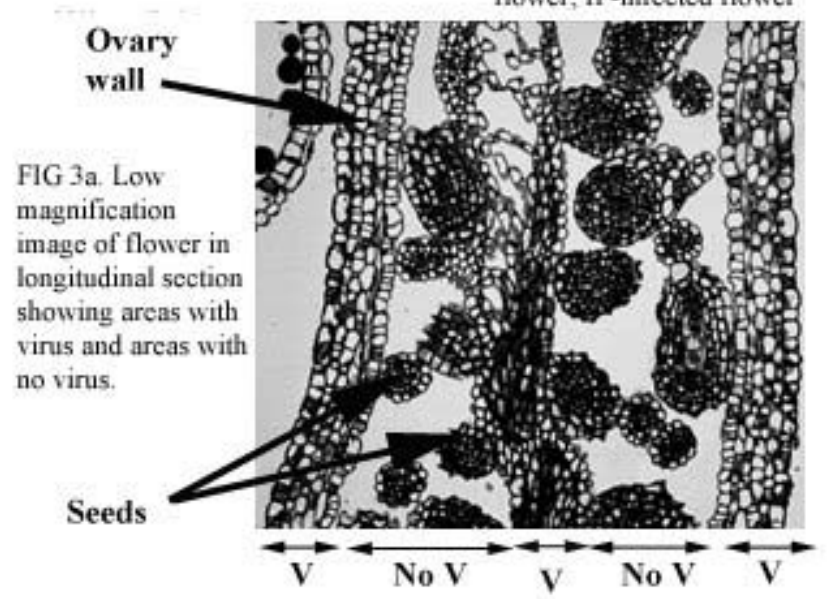

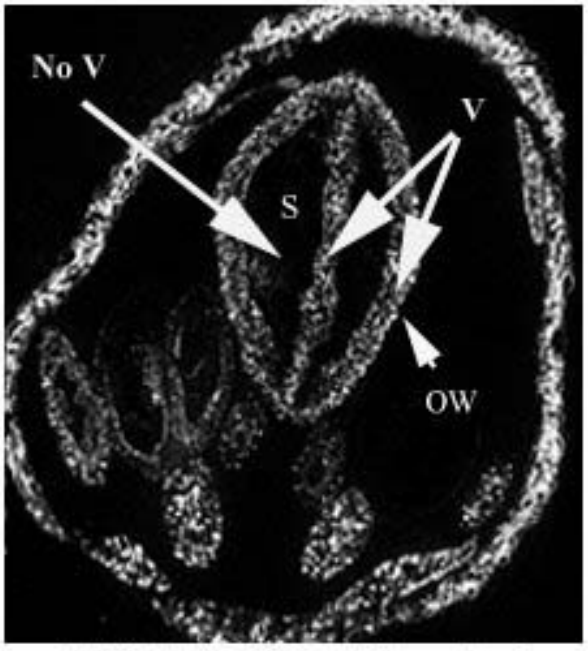

FIG. 2, Confocal image of flower showing presence of virus in all parts of flower except seeds (S). Anti-TVCP CP was reacted with $\mathrm{Cy}-5$ conjugated seconday antibody.

$\mathrm{OW}$ - ovary wall; V-virus; No V-No virus

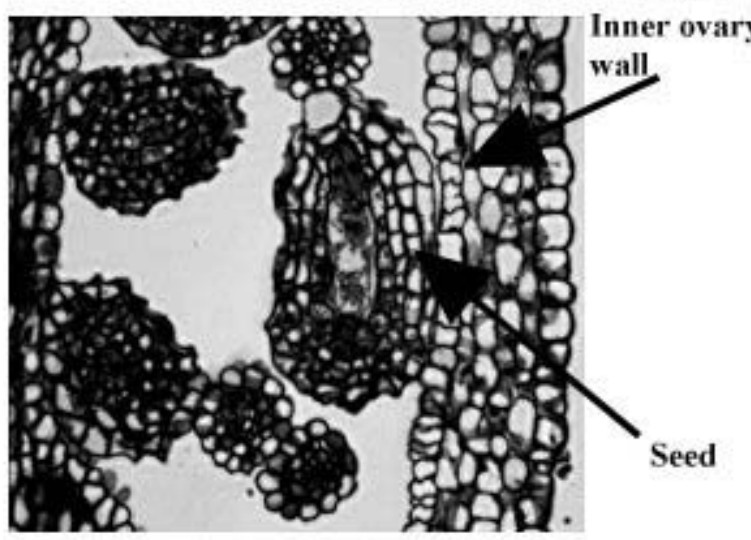

FIG, 3b. High magnification image of flower showing inner ovary wall and seeds inside ovary.

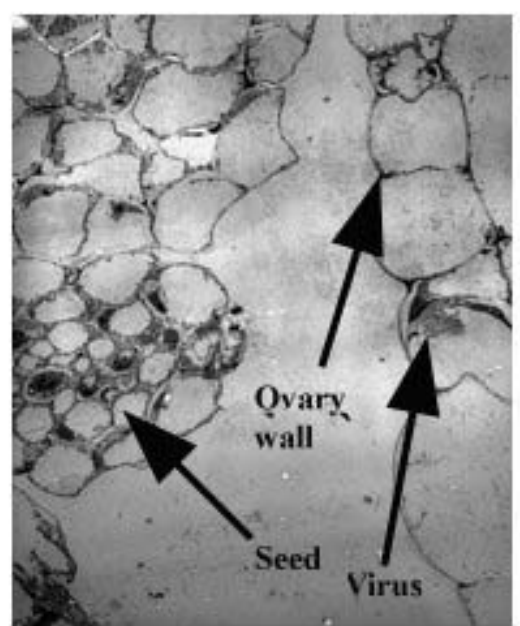

$\bar{F} \bar{G}$. 4a. Low magnification TEMM image shows viral particles in innermost cell layer of ovary wall, facing seeds.

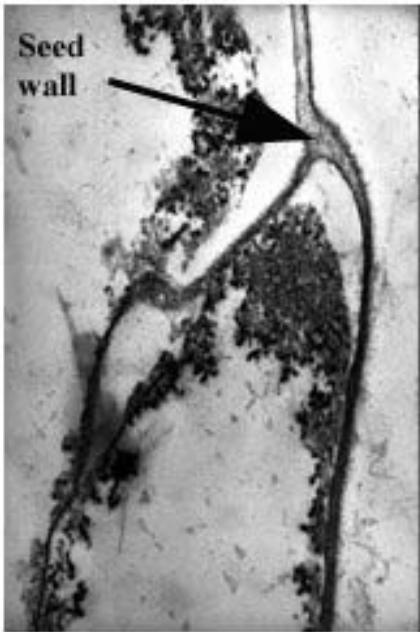

FIG. $4 \mathrm{~b}$. High magnification TEM image of seed showing thin wall and absence of viral particles.

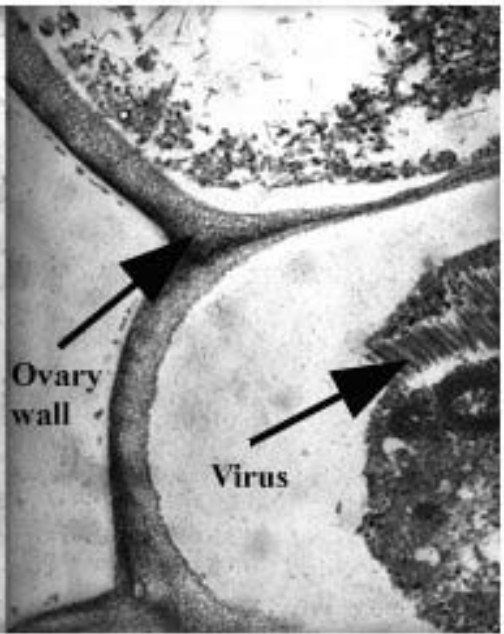

FIG. 4c. Innermost cell layer of ovary shows thickening of wall and viral particles are present.

\footnotetext{
16.5 . microns
}

7.5 microns

7.5 microns 